\title{
Preserved insulin secretion and kidney function in recipients with functional pancreas grafts 1 year after transplantation: a single-center prospective observational study
}

\author{
Espen Nordheim ${ }^{1,2}$, Kåre I Birkeland 1,2, Anders Åsberg ${ }^{1,3}$, Anders Hartmann ${ }^{1,2}$, Rune Horneland ${ }^{4}$ and \\ Trond Jenssen ${ }^{1,5}$
}

'Department of Transplantation Medicine, Section of Nephrology, Oslo University Hospital, Rikshospitalet, Oslo, Norway, ${ }^{2}$ Faculty of Medicine, ${ }^{3}$ School of Pharmacy, University of Oslo, Oslo, Norway, ${ }^{4}$ Department of Transplantation Medicine, Section of Transplantation Surgery, Oslo University Hospital, Rikshospitalet, Oslo, Norway, and ${ }^{5}$ Metabolic and Renal Research Group, Faculty of Health Sciences, UiT- The Arctic University of Norway, Tromsø, Norway

Correspondence should be addressed to E Nordheim Email b23697@ous-hf.no

\begin{abstract}
Objective: Successful simultaneous pancreas and kidney transplantation (SPK) or pancreas transplantation alone (PTA) restores glycemic control. Diabetes and impaired kidney function are common side effects of immunosuppressive therapy. This study addresses glucometabolic parameters and kidney function during the first year.

Methods: We examined 67 patients with functioning grafts (SPK $n=30$, PTA $n=37$ ) transplanted between September 2011 and November 2016 who underwent repeated oral glucose tolerance tests (OGTTs) 8 and 52 weeks after transplantation. Another 19 patients lost their graft the first year post-transplant and 28 patients did not undergo repeated OGTTs and could not be studied. All patients received ATG induction therapy plus tacrolimus, mycophenolate and prednisolone. Glomerular filtration rate was measured before and 8 and 52 weeks after transplantation by serum clearance methods.

Results: From week 8 to 52 after transplantation, mean fasting glucose decreased (SPK: $5.4 \pm 0.7$ to $5.1 \pm 0.8 \mathrm{mmol} / \mathrm{L}$, PTA: $5.4 \pm 0.6$ to $5.2 \pm 0.7 \mathrm{mmol} / \mathrm{L}$; both $P<0.05$ ), and also 120 - $\mathrm{min}$ post-OGTT glucose (SPK: $6.9 \pm 2.9$ to $5.7 \pm 2.2 \mathrm{mmol} / \mathrm{L}$; $P=0.07$, PTA: $6.5 \pm 1.7$ to $5.7 \pm 1.2 \mathrm{mmol} / \mathrm{L} ; P<0.05$ ). Fasting C-peptide levels also decreased (SPK: $1500 \pm 573$ to $1078 \pm 357 \mathrm{pmol} / \mathrm{L}, \mathrm{PTA}: 1210 \pm 487$ to $1021 \pm 434 \mathrm{pmol} / \mathrm{L}$, both $P<0.005)$. Measured GFR decreased from enlistment to 8 weeks post transplant in PTA patients $\left(94 \pm 22\right.$ to $\left.78 \pm 19 \mathrm{~mL} / \mathrm{min} / 1.73 \mathrm{~m}^{2} ; P<0.005\right)$, but did not deteriorate from week 8 to week 52 (SPK: $55.0 \pm 15.1$ vs $59.7 \pm 11.3 \mathrm{ml} / \mathrm{min} / 1.73 \mathrm{~m}^{2} ; P=0.19$, PTA: $76 \pm 19$ vs $77 \pm 19 \mathrm{~mL} / \mathrm{min} / 1.73 \mathrm{~m}$; $P=0.74)$.

Conclusion: Glycemic control and kidney function remain preserved in recipients with functioning SPK and PTA grafts 1 year after transplantation.

European Journal of Endocrinology

(2018) 179, 251-259
\end{abstract}

(C) 2018 European Society of Endocrinology Printed in Great Britain
Published by Bioscientifica Ltd. 


\section{Introduction}

Simultaneous pancreas and kidney (SPK) transplantation has become an established treatment for patients with type 1 diabetes and end-stage kidney disease (1). Pancreas transplantation alone (PTA) is offered to selected patients with life-threatening brittle diabetes $(2,3)$.

Successful pancreas transplantation (PTX) has several advantages: restoration of normal blood glucose, insulin independence and reversal of hypoglycemic unawareness, the latter can be of crucial importance for selected patients. PTX may also have beneficial effects on the progression of diabetic nephropathy, retinopathy, neuropathy and atherosclerotic cardiovascular disease (4). Advances in both surgical technique and immunosuppressive therapy have improved long-term results after PTX, but the results are still inferior to other solid abdominal organ transplantations (5), mainly due to surgical complications and rejections (6). Immunosuppressive therapy may have diabetogenic effects. Steroids stimulate gluconeogenesis and glycogenolysis, increase hepatic glucose production and induce peripheral insulin resistance (7) while calcineurin inhibitors (CNIs) may reduce insulin secretion $(8,9)$. Furthermore, CNIs may deteriorate kidney function due to their nephrotoxic effect. PTA recipients who already have developed diabetes nephropathy may experience additional risk for renal failure. On the other hand, successful PTA is associated with restoration of normal blood glucose which could counteract diabetes-associated progression of kidney injury.

In order to improve our understanding of glucose metabolism and kidney function after pancreas transplantation, we assessed parameters of insulin secretion and action together with renal function 8 and 52 weeks after successful SPKs and PTAs performed at our center.

\section{Subjects and methods}

This single-center prospective observational study included 114 consecutive Caucasian patients who underwent PTX in Norway from September 2012 till November 2016.

Recipients who lost their graft during the first year after transplantation $(n=19)$ were excluded (Fig. 1: Flow chart). Ninety-five recipients (SPK $n=47$, PTA $n=48$ ) had a well- functioning pancreas grafts 1 year after transplantation without use of insulin or other glucoselowering drugs. Sixty-seven recipients were evaluated with repeated oral glucose tolerance tests (OGTTs) at

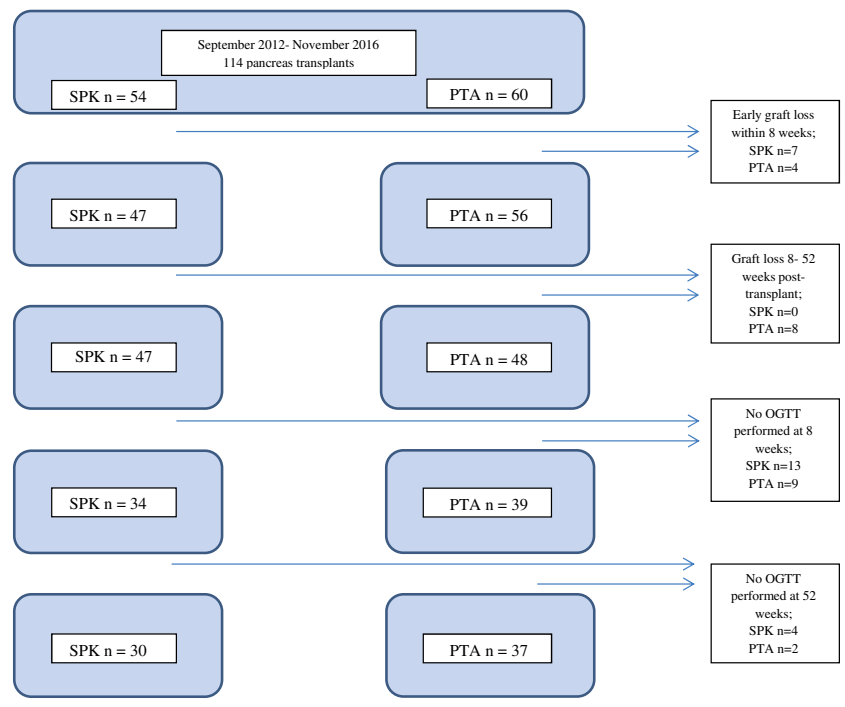

\section{Figure 1}

Flow chart of patient selection in the study.

week 8 and 52 after transplantation and were included in the analysis. Twenty-eight patients did not perform these investigations due to interfering conditions such as infection, acute rejection episodes or were in isolation as antibiotic- resistant bacteria were detected.

All recipients received pancreas transplants with duodeno-duodenal exocrine drainage and systemic venous drainage to the inferior cava vein by an iliac allograft vein as an elongation of the portal vein (10). Patients with type 1 diabetes mellitus (DM) and measured GFR (mGFR) below $20 \mathrm{~mL} / \mathrm{min} / 1.73 \mathrm{~m}^{2}$ were listed as SPK candidates while patients with type $1 \mathrm{DM}$, 'Brittlediabetes' and $\mathrm{mGFR}>30 \mathrm{~mL} / \mathrm{min} / 1.73 \mathrm{~m}^{2}$ were listed as candidates for PTA. Data for the two recipient groups are presented separately since they were recruited from two different patient pools.

Thirty PTX recipients underwent simultaneous pancreas and kidney transplantation (SPK) while 37 underwent PTA. Out of the 37 PTA patients, two patients had pancreas transplantation after kidney transplantation, two patients had pancreas transplantation after islet transplantation and one patient had pancreas re-transplantation after SPK transplantation. The three patients with former renal transplants were excluded from the PTA group in the analysis of measured GFR before and after pancreas transplantation.

Both recipient groups were given similar immunosuppressive therapy, including induction therapy with ATG (Thymoglobulin) and standard maintenance tacrolimus treatment (tacrolimus trough levels of 10-12 tapered to $6-10 \mu \mathrm{g} / \mathrm{L}$ by 8 weeks), mycophenolate mofetil 
(MMF) $1 \mathrm{~g}$ twice daily and steroids (tapered to $10 \mathrm{mg} /$ day by week 4 and $5 \mathrm{mg} /$ day by week 26). One patient was given azathioprine instead of MMF due to mycophenolate intolerance.

Measured GFR and OGTT investigations were scheduled on the same day and performed in the same laboratory at the transplant center at 8 and 52 weeks after transplantation. The OGTT was performed after at least $8 \mathrm{~h}$ of fasting with oral administration of $75 \mathrm{~g}$ glucose in $200 \mathrm{~mL}$ of water. Patients were instructed to stay on a weight-maintaining diet for 3 days prior to testing and abstain from alcohol. Glucose, insulin and C-peptide were measured just prior to, and 30 and $120 \mathrm{~min}$ after, the glucose load. Measured GFR was performed by the 2-point iohexol serum clearance method, starting with normal plasma glucose after the OGTT. Extended laboratory tests and assessment of clinical parameters were performed in the same session. The insulinogenic index (Insulin ${ }_{30^{-}}$ Insulin $_{0} /$ Glucose $_{30}$-glucose ${ }_{0}$, IGI) (11), and area under the concentration vs time curve (AUC) for glucose, insulin and C-peptide, were calculated from the OGTT data. As $\mathrm{C}$-peptide is affected by kidney function, the quotient of fasting C-peptide/fasting glucose $\times \mathrm{P}$-creatinine was also calculated (12).

Homeostasis model assessment of insulin resistance $\left(\mathrm{HOMA} 2_{\mathrm{IR}}\right)$ and beta cell function $\left(\mathrm{HOMA}_{\mathrm{B} \%}\right)$ were calculated according to the fasting glucose and plasma C-peptide levels by the Web-based HOMA 2 calculator (13). C-peptide was used in these calculations as it is less confounded than insulin with regards to the missing first pass effect of the liver in pancreas grafts with caval venous drainage (14). We also calculated the ratio IGI/HOMA2 $2_{\mathrm{IR}}$ with the intention of adjusting insulin secretion to insulin resistance.

All patients had their pre-transplantwork-upperformed in local hospitals before they were referred to the national transplant center. All PTA candidates had measured GFR investigations performed locally with plasma clearance methods according to center praxis, mostly ${ }^{51} \mathrm{Cr}$-EDTA, as part of the work-up. The pre-transplant measurements represent variables sampled while the patients were on the waiting lists for transplantation; BMI, HbA1c, CMV IgG, blood pressure measurements, medication lists and urine albumin/creatinine results were collected for all pancreas transplant candidates, in order to compare pre- and posttransplant levels in this study.

Data included in this quality study were retrieved from the transplantation database at our center and analyses were performed on de-identified data. All patients who are included in the database gave written consent for saving their clinical data and to use them in research and quality assessment studies. According to national guidelines, there was consequently no need for ethics approval for this quality analyses, but the quality study was approved by the Norwegian Data Inspectorate.

\section{Data collection and statistical analyses}

This is a retrospective analysis of prospectively collected data. Data analysis was performed using SPSS (version 22; IBM, Armonk, NY, USA). Categorical outcomes are described using frequencies and proportions while continuous variables are described using mean \pm s.D. Group comparisons were performed by a Student's $t$-test, chi-square test or Fishers' exact test when appropriate. $P$ values were reported according to two-tailed analysis, and $P$ values $<0.05$ were considered statistically significant.

\section{Results}

Baseline characteristics of the two groups are presented in Table 1. It was a higher share of men in the SPK than in the PTA group (73 vs 51\%) and the mean pre-transplant mGFR was, by selection, higher in the PTA group. The groups were otherwise comparable with regards to age, duration of diabetes, daily doses of insulin, HbA1c, BMI and degree of HLA mismatches at transplantation. Stable simplex retinopathy with no signs of proliferative changes was confirmed by ophthalmologic examination prior to wait listing. The 28 patients who did not perform the investigations at week 8 did not differ with regards to the patient characteristics listed in Table 1 . The fourteen patients who performed the investigations at 8 weeks but not at 52 weeks had comparable OGTT results at 8 weeks as those repeating the investigation at week 52 (data not shown). Mean prednisolone doses and tacrolimus through concentrations declined, in accordance with the center protocol, from week 8 to week 52 for both SPK and PTA recipients (Table 2).

\section{Simultaneous pancreas and kidney transplant (SPK) recipients}

Among 30 included SPK recipients, 15 were CMV IgG negative pre transplant. Thirteen of the latter (87\%), who were transplanted with grafts from CMV IgG-positive donors, received prophylactic treatment with $900 \mathrm{mg}$ valganciclovir once daily for 6 months (doses adjusted to renal function). 
Table 1 Baseline characteristics of SPK and PTA recipients before transplantation.

\begin{tabular}{|c|c|c|}
\hline & SPK $(n=30)$ & PTA $(n=37)$ \\
\hline Age & $42.4 \pm 6.5$ & $41.7 \pm 9.9$ \\
\hline Males (\%) & $22(73 \%)$ & $19(51 \%)$ \\
\hline Duration of diabetes (years) & $30.6 \pm 6.4$ & $26.6 \pm 10.5$ \\
\hline Daily dose of insulin (IU) & $39.5 \pm 13.1$ & $49.9 \pm 22.3$ \\
\hline \multicolumn{3}{|l|}{ HLA mismatch (\%) } \\
\hline $1-2$ & $1(3 \%)$ & 0 \\
\hline $3-4$ & $9(30 \%)$ & $17(46 \%)$ \\
\hline $5-6$ & $20(67 \%)$ & $20(54 \%)$ \\
\hline HbA1c (\%) & $8.5 \pm 1.5$ & $8.9 \pm 1.5$ \\
\hline $\mathrm{HbA} 1 \mathrm{c}(\mathrm{mmol} / \mathrm{mol})$ & $69.6 \pm 16.7$ & $73.7 \pm 16.4$ \\
\hline BMI $\left(\mathrm{kg} / \mathrm{m}^{2}\right)$ & $23.5 \pm 3.1$ & $25.8 \pm 3.5$ \\
\hline Measured GFR $\left(\mathrm{mL} / \mathrm{min} / 1.73 \mathrm{~m}^{2}\right)$ & $<30$ & $94^{a} \pm 22$ \\
\hline
\end{tabular}

aThree patients were excluded from the PTA group in the analysis of measured GFR due to prior kidney transplantation.

The mean blood pressure was $141 \pm 22 / 81 \pm 11 \mathrm{mmHg}$ pre transplant, $134 \pm 21 / 78 \pm 12 \mathrm{mmHg}$ at 8 weeks post transplant and $134 \pm 15 / 76 \pm 10 \mathrm{mmHg}$ at 52 weeks post transplant. Eighty-three percent of SPK recipients were treated with antihypertensive medication pre transplant, while $34 \%$ were treated with antihypertensive medication at 8 weeks and 52 weeks post transplant, respectively.

The mean urine albumin/creatinine ratio was $326 \pm 256 \mathrm{mg} / \mathrm{mmol}$ pre transplant, $4.9 \pm 5.4 \mathrm{mg} / \mathrm{mmol}$ 8 weeks post transplant and $3.2 \pm 6.8 \mathrm{mg} / \mathrm{mmol} 52$ weeks post transplant.

Six SPK recipients had rejection episodes in either organ. One recipient had simultaneous rejections in kidney and pancreas graft, one recipient had solitary kidney graft rejection and four patients had solitary pancreas graft rejection. Five of these patients developed rejection within the first 8 weeks post transplant.

Mean tacrolimus trough level was $9.6 \pm 2.2 \mu \mathrm{g} / \mathrm{L}$ at 8 weeks post transplant and $7.8 \pm 2.2 \mu \mathrm{g} / \mathrm{L}$ at 52 weeks post transplant. At 8 weeks post transplant, the protocolbased maintenance dose of prednisolone was $10 \mathrm{mg}$ while the accumulated dose was $760 \mathrm{mg}$. At 52 weeks post transplant, protocol-based maintenance dose was $5 \mathrm{mg}$ while the accumulated dose was $2625 \mathrm{mg}$.

Eight weeks after transplantation, BMI and HbA1c were significantly reduced when compared to status pre-transplant; BMI fell from $23.5 \pm 3.1 \mathrm{~kg} / \mathrm{m}^{2}$ to $22.7 \pm 2.4 \mathrm{~kg} / \mathrm{m}^{2}(P=0.01)$ and HbA1c from $69.6 \pm 16.7$ to $36.8 \pm 8.2 \mathrm{mmol} / \mathrm{mol}(8.5 \pm 1.5$ to $5.6 \pm 0.7 \% ; P<0.005)$.

The changes from 8 weeks to 52 weeks are shown in Table 2. HbA1c was 36.8 and $36.4 \mathrm{mmol} / \mathrm{mol}$ (5.6 and $5.5 \% ; P=0.72$ ) at weeks 8 and 52 respectively. Mean fasting plasma glucose, C-peptide and the quotient of C-peptide (glucose $\times$ creatinine) decreased significantly. The mean C-peptide levels at $120 \mathrm{~min}$ were also lower (Fig. 2). Finally AUC $_{120}$ C-peptide, HOMA2 $2_{\text {IR }}$ and IGI/HOMA2 $2_{\text {IR }}$ decreased from week 8 to week 52, whereas the other parameters of glucose metabolism did not change significantly.

Measured GFR did not change significantly between weeks 8 and 52 (Table 2).

There was no significant correlation between change in fasting c-peptide values from week 8 to week 52 post transplant and measured GFR at week 52 post transplantation (Pearson correlation: $-0.28 ; P=0.19$ ). A correlation was found between change in fasting c-peptide values between week 8 and week 52 post transplantation and level of increasing urine albumin/creatinine level at week 52 post transplantation (Pearson correlation: 0.38 ; $P=0.04)$.

SPK recipients who were not treated with hypertensive medication at week 52 post transplant had no significant difference in change of fasting c-peptide values between week 8 and week 52 post transplantation, compared to the recipients who were treated with such medication (mean $404 \pm 484 \mathrm{pmol} / \mathrm{L} / 440 \pm 395 \mathrm{pmol} / \mathrm{L} ; P=0.41$ ).

\section{PTA recipients}

Of the 37 included PTA recipients, 19 were CMV IgG negative pre transplant. Eleven of these recipients (58\%) were transplanted with grafts from CMV IgG-positive donors and received prophylactic treatment with valganciclovir for 6 months.

Mean blood pressure was $127 \pm 12 / 77 \pm 10 \mathrm{mmHg}$ pre transplant, $129 \pm 14 / 77 \pm 7 \mathrm{mmHg} 8$ weeks post transplant and $126 \pm 11 / 77 \pm 8 \mathrm{mmHg} 52$ weeks post transplant. Thirty-eight percent of the PTA recipients were treated with antihypertensive medication pre transplant, $18 \%$ at 8 weeks and $26 \%$ at 52 weeks post transplant.

The mean urine albumin/creatinine ratio was $21.7 \pm 69.0 \mathrm{mg} / \mathrm{mmol}$ pre transplant, $6.7 \pm 16.0 \mathrm{mg} / \mathrm{mmol}$ 8 weeks post transplant and $9.7 \pm 22.3 \mathrm{mg} / \mathrm{mmol} 52$ weeks post transplant.

Sixteen PTA recipients had at least 1 rejection episode during the study period; 2 recipients had two rejection episodes while 14 recipients had one rejection episode during the first year post transplant. Fifteen of these recipients developed rejection within the first 8 weeks post transplant, while two recipients developed rejection between week 8 and week 52 post transplant.

Mean tacrolimus trough level was $9.4 \pm 2.4 \mu \mathrm{g} / \mathrm{L}$ at 8 weeks post transplant and $7.5 \pm 2.5 \mu \mathrm{g} / \mathrm{L}$ at 52 weeks 


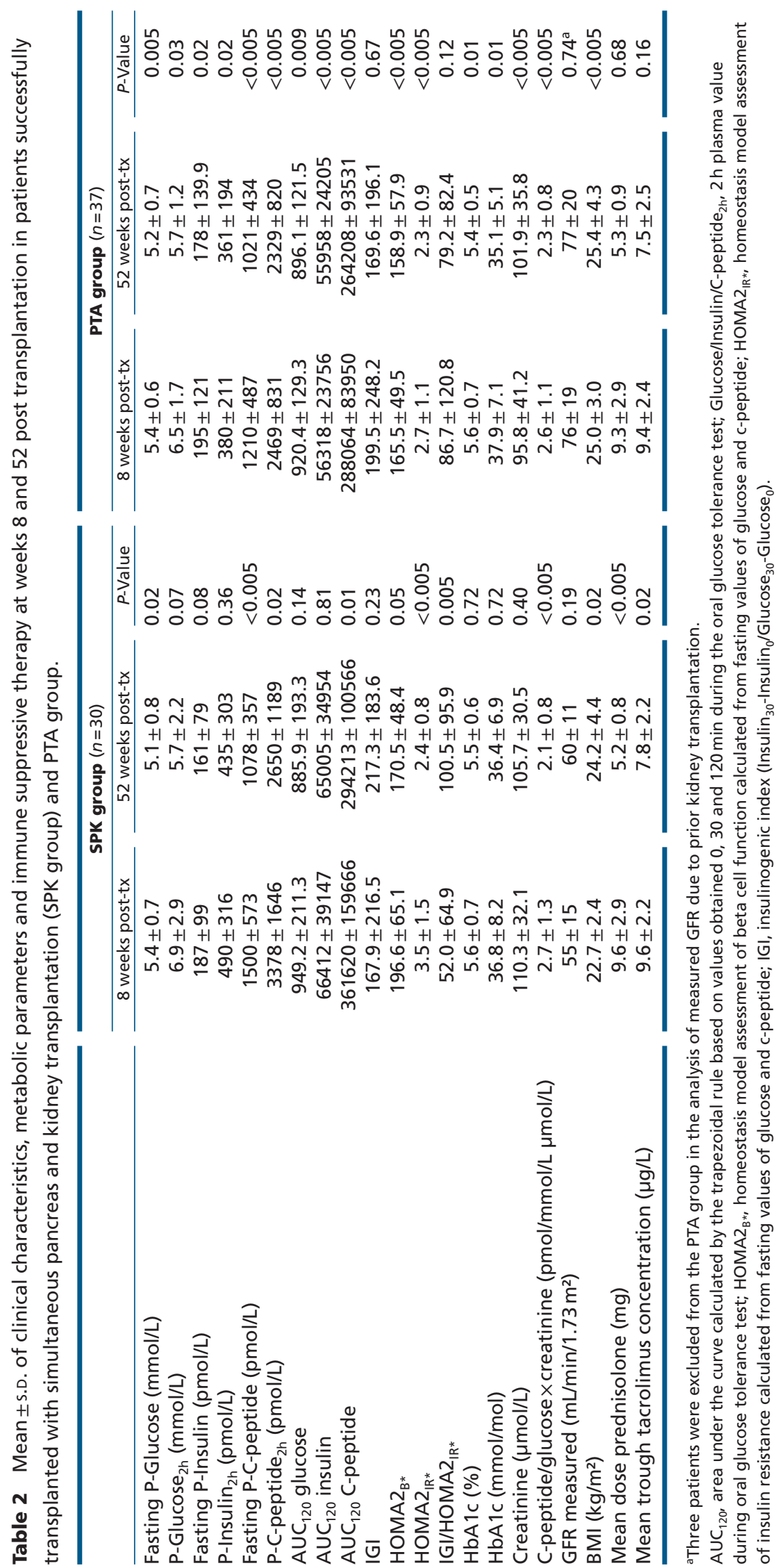



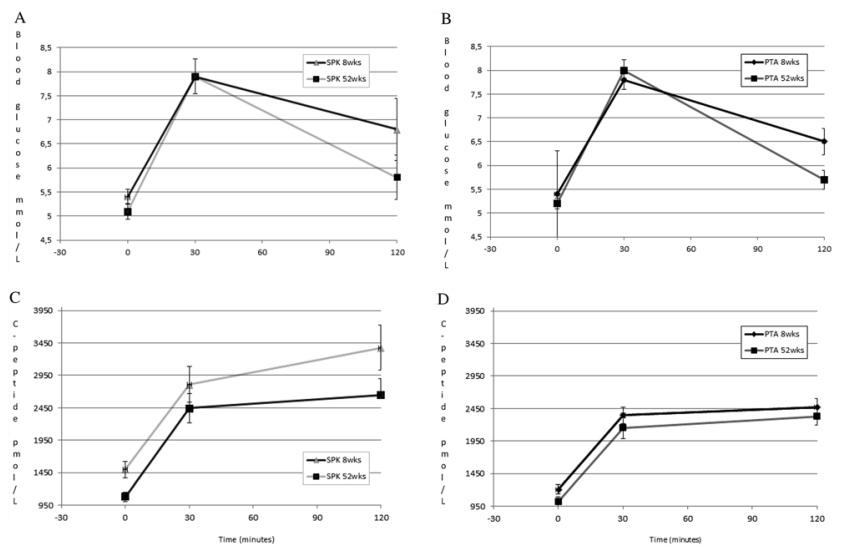

Figure 2

OGTT results for blood glucose measured at 8 weeks and 52 weeks post transplant for SPK (A) and PTA recipients (B) and C-peptide measured at 8 weeks and 52 weeks post transplant for SPK (C) and PTA recipients (D) referred as mean \pm S.E.M.

post transplant. At 8 weeks post transplant the protocolbased maintenance dose of prednisolone was $10 \mathrm{mg}$ while the accumulated dose was $760 \mathrm{mg}$. At 52 weeks post transplant protocol-based maintenance dose was $5 \mathrm{mg}$ while the accumulated dose was $2625 \mathrm{mg}$.

Eight weeks after transplantation BMI and HbA1c were significantly reduced when compared to status pretransplant; BMI was reduced from $25.8 \pm 3.5 \mathrm{~kg} / \mathrm{m}^{2}$ to $25.0 \pm 3.0 \mathrm{~kg} / \mathrm{m}^{2}(P=0.006)$ and HbA1c from $73.7 \pm 16.4$ to $37.9 \pm 7.1 \mathrm{mmol} / \mathrm{mol}(8.9 \pm 1.5 \%$ to $5.6 \pm 0.7 \% ; P<0.005)$.

The changes from 8 weeks to 52 weeks are shown in Table 2. HbA1c was further reduced from 37.9 to $35.1 \mathrm{mmol} / \mathrm{mol}$ (5.6 to $5.4 \%, P=0.01)$. Mean fasting plasma glucose, insulin, C-peptide and the quotient of C-peptide/(glucose $\times$ creatinine) decreased significantly. Mean glucose, insulin and C-peptide levels at $120 \mathrm{~min}$ also decreased significantly (Fig. 2). Finally AUC $_{120}$ for glucose, insulin and C-peptide and also $\mathrm{HOMA}_{\mathrm{IR}}$ and $\mathrm{HOMA} 2_{\mathrm{B}}$ decreased from week 8 to week 52 .

Measured GFR decreased from the time the patients were listed for transplantation until week eight after transplantation $\left(94 \pm 22\right.$ to $78 \pm 19 \mathrm{~mL} / \mathrm{min} / 1.73 \mathrm{~m}^{2}$; $P<0.005)$ while no change was observed from week 8 to week 52 (Table 2).

BMI increased from week 8 to week 52 after transplantation.

There was no significant correlation between change in fasting c- peptide values from week 8 to week 52 post- transplant and measured GFR at week 52 post transplantation (Pearson correlation coefficient:
-0.17; $P=0.35)$. Furthermore, there was no significant correlation between change in fasting c-peptide values between week 8 and week 52 post transplantation and level of urine albumin/creatinine level at week 52 post transplantation (Pearson correlation: 0.03; $P=0.87$ ). PTA recipients who were not treated with hypertensive medication at week 52 post transplant, had no significant difference in change of fasting c-peptide values between week 8 and week 52 post transplantation, compared to the recipients who were treated with such medication (mean $234 \pm 327 \mathrm{pmol} / \mathrm{L} / 164 \pm 272 \mathrm{pmol} / \mathrm{L} ; P=0.49$ ).

\section{Discussion}

Our main findings are that glucose control and mGFR are preserved 1 year after successful pancreas transplantation. Insulin secretion decreases in parallel with lower insulin resistance.

In contrast to most publications reporting on glucose metabolism after pancreas transplantation, our material consists of a majority of PTA recipients. In patients with functioning pancreas transplant grafts the mean levels of glucose and C-peptide were found significantly reduced after 1 year, but still within the normal range for both PTA and SPK recipients. Preserved glucose homeostasis after pancreas transplantation has been reported even 15 years after transplantation in selected patients (15). Dieterle et al. found a slight and continuous increase of fasting glucose within the normal range in their study of insulin-independent SPK recpients who were followed with OGTTs for over 10 years. Luzi et al. demonstrated that euglycaemic-hyperinsulinaemic clamp determined insulin sensitivity normalized in six SPK patients after 12 months in their study(16).

Insulin response in target cells is not only dependent on plasma insulin concentrations, but also on insulin sensitivity. State-of-the-art measurement of insulin sensitivity is performed with an euglycaemichyperinsulinaemic clamp technique (17), but the technique is not suitable for routine clinical use and was not available to us in the present study. Insulin resistance and beta-cell function have been estimated in large groups of patients from fasting glucose and insulin levels, e.g. with the homeostasis model assessment (HOMA) (18). HOMA calculations of beta cell function and insulin resistance $\left(\mathrm{HOMA}_{\mathrm{B} \%}\right.$ and $\mathrm{HOMA}_{\mathrm{IR}}$ ) are validated for patients with various degrees of glucose intolerance, but less so for transplant recipients. As our pancreas transplant recipients drain insulin to the systemic and not to the 
portal circulation, the liver and the periphery are exposed to similar levels of insulin.

In our patients, who did not have any need for glucose-lowering agents or insulin, the insulin secretion seems well preserved both 8 weeks and 1 year after transplantation. HOMA2 $2_{\mathrm{IR}}$ was lower 1 year post transplant for both recipient groups despite increase in BMI. Given the change in $\mathrm{HOMA} 2_{\mathrm{IR}}$ represents true improvement in insulin sensitivity, it is most likely caused by tapering of immunosuppressive agents in the same period.

Successful pancreas transplantation normalizes blood glucose, which could reduce the progression of diabetic nephropathy (19), but immunosuppression and other transplant-related factors may on the other hand affect renal function negatively. One year after pancreas transplantation, the renal function in both transplanted and native kidneys were well preserved in our patients. The five-year cumulative risk for end-stage renal disease in patients undergoing non-renal organ transplantation has been reported to be $10.9 \%$ after heart transplantation and $18.1 \%$ after liver transplantation, and treatment with calcineurin inhibitors, age and era of transplantation are among risk factors that could explain this (20). Reports on renal function after pancreas transplantation are mostly case series and with partly conflicting results. Decline in renal function 5 years after PTA was observed by Le Dinh (21). In fact, deterioration of renal function may be observed regardless of pre-transplant renal function (22). Others have reported that pre-transplant renal function may be of importance: PTA recipients with creatinine clearance below $70 \mathrm{~mL} / \mathrm{min} / 1.73 \mathrm{~m}^{2}$ before transplantation had a significant risk of worsened renal function after transplantation in one study (23), while another report suggested that native renal function declined only in PTA recipients with pre-transplant GFR $>90 \mathrm{~mL} / \mathrm{min} / 1.73 \mathrm{~m}^{2}$ possibly due to correction of hyperfiltration as a result of normalized glucose levels (24).

Our PTA patients had mGFRs ranging $35-134 \mathrm{~mL} /$ $\mathrm{min} / 1.73 \mathrm{~m}^{2}$ before transplantation, and only seven patients had mGFR $<70 \mathrm{~mL} / \mathrm{min} / 1.73 \mathrm{~m}^{2}$. Our PTA recipients also showed a significant decline in mGFR from the time they were listed for transplantation until 8 weeks after transplantation during median waiting time 199 days (range 28-500). The decline in renal function after pancreas transplantation may support the findings by Buggi et al. (24).

Immunosuppressive therapy may affect both insulin secretion and sensitivity, as well as renal function negatively after transplantation. Our maintainence immuosuppressive protocol included use of $5 \mathrm{mg}$ prednisolone, and our center has previsously reported that withdrawal of such a dose does not improve insulin sensitivity measured by a hyperinsulinemiceuglycemic clamp technique (25). Others have reported that tacrolimus and cyclosporine do not differ regarding their effects on glucose metabolism and insulin secretory capacity 3 years after SPK (26). In renal transplant recipients, however, insulin sensitivity has been found to be negatively correlated with trough levels of tacrolimus (27). Chatzizacharias et al. found that high tacrolimus trough levels at 6 months post transplant were the only independent risk factor for decline in renal function in PTA recipients over 2 years (28). All our patients were treated with tacrolimus at lower trough levels 1 year compared to 8 weeks after transplantation.

The strength of our study is the sample size, and that it is a national cohort and the longitudinal design. All included patients were transplanted at the national transplant center with the same surgical technique, treated according to the same immunosuppressive protocol and all underwent a standardized follow-up. Renal function was assessed using mGFR, which is more precise than estimated GFR by creatinine or cystatin C algorithms. The major limitations of our study are the fact that only $60 \%$ of all patients transplanted in the study time period were included in the analyses, as we excluded the patients who were not investigated with OGTTs twice. Unfortunately, we do not have follow-up data for changes in retinopathy or neuropathy (neither peripheral nor autonomous neuropathy). The restricted follow-up period of 1 year is also a limitation of the study.

Our findings are reassuring since they indicate that patients undergoing clinically successful pancreas transplantation maintain normal glucose homeostasis as measured by C-peptide indices and that kidney function is stable, at least during the first year after transplantation. Interpretation of our results must be done in light of the inclusion criteria of the study.

\section{Declaration of interest}

The authors declare that there is no conflict of interest that could be perceived as prejudicing the impartiality of this study.

\section{Funding}

This research did not receive any specific grant from any funding agency in the public, commercial or not-for-profit sector. 
Author contribution statement

E N, K I B and T J developed the study concept and design, performed the analysis and interpretation of data, drafted the manuscript, performed critical revision of the manuscript for important intellectual content and performed statistical analysis. A H, R H and A A performed critical revision of the manuscript for important intellectual content.

\section{Acknowledgements}

$\mathrm{EN}$ is the guarantor of this work and, as such, had full access to all the data in the study and takes responsibility for the integrity of the data and the accuracy of the data analysis.

\section{References}

1 Dholakia S, Mittal S, Quiroga I, Gilbert J, Sharples EJ, Ploeg RJ \& Friend PJ. Pancreas transplantation: past, present, future. American Journal of Medicine 2016129 667-673. (https://doi.org/10.1016/j. amjmed.2016.02.011)

2 Gruessner RW \& Gruessner AC. Pancreas transplant alone: a procedure coming of age. Diabetes Care 201336 2440-2447. (https:// doi.org/10.2337/dc12-2195)

3 Gruessner RW \& Gruessner AC. The current state of pancreas transplantation. Nature Reviews Endocrinology 20139 555-562. (https://doi.org/10.1038/nrendo.2013.138)

4 Dean PG, Kukla A, Stegall MD \& Kudva YC. Pancreas transplantation. BMJ 2017357 j1321. (https://doi.org/10.1136/bmj.j1321)

5 Laftavi MR, Gruessner A \& Gruessner R. Surgery of pancreas transplantation. Current Opinion in Organ Transplantation 201722 389-397. (https://doi.org/10.1097/MOT.0000000000000434)

6 Lindahl JP, Horneland R, Nordheim E, Hartmann A, Aandahl EM, Grzyb K, Haugaa H, Kjosen G, Asberg A \& Jenssen T. Outcomes in pancreas transplantation with exocrine drainage through a duodenoduodenostomy versus duodenojejunostomy. American Journal of Transplantation 201818 154-162. (https://doi.org/10.1111/ ajt.14420)

7 Rooney DP \& Robertson RP. Hepatic insulin resistance after pancreas transplantation in type I diabetes. Diabetes 199645 134-138. (https://doi.org/10.2337/diab.45.2.134)

8 Ozbay LA, Smidt K, Mortensen DM, Carstens J, Jorgensen KA \& Rungby J. Cyclosporin and tacrolimus impair insulin secretion and transcriptional regulation in INS-1E beta-cells. British Journal of Pharmacology 2011162 136-146. (https://doi.org/10.1111/j.14765381.2010.01018.x)

9 Rodriguez-Rodriguez AE, Trinanes J, Velazquez-Garcia S, Porrini E, Vega Prieto MJ, Diez Fuentes ML, Arevalo M, Salido Ruiz E \& Torres A. The higher diabetogenic risk of tacrolimus depends on pre-existing insulin resistance. A study in obese and lean Zucker rats. American Journal of Transplantation 201313 1665-1675. (https://doi. org/10.1111/ajt.12236)

10 Horneland R, Paulsen V, Lindahl JP, Grzyb K, Eide TJ, Lundin K, Aabakken L, Jenssen T, Aandahl EM, Foss A et al. Pancreas transplantation with enteroanastomosis to native duodenum poses technical challenges - but offers improved endoscopic access for scheduled biopsies and therapeutic interventions. American Journal of Transplantation 201515 242-250. (https://doi.org/10.1111/ajt.12953)

11 Pacini G \& Mari A. Methods for clinical assessment of insulin sensitivity and beta-cell function. Best Practice and Research: Clinical Endocrinology and Metabolism 200317 305-322. (https://doi. org/10.1016/S1521-690X(03)00042-3)

12 Faradji RN, Monroy K, Messinger S, Pileggi A, Froud T, Baidal DA, Cure PE, Ricordi C, Luzi L \& Alejandro R. Simple measures to monitor beta-cell mass and assess islet graft dysfunction. American
Journal of Transplantation 20077 303-308. (https://doi.org/10.1111/ j.1600-6143.2006.01620.x)

13 Oxford TUo. HOMA Calculator. 2018. https://www.dtu.ox.ac.uk/ homacalculator/download.php. Accessed and downloaded June 30, 2017.

14 Bazerbachi F, Selzner M, Marquez MA, Norgate A, Aslani N, McGilvray ID, Schiff J \& Cattral MS. Portal venous versus systemic venous drainage of pancreas grafts: impact on long-term results. American Journal of Transplantation 201212 226-232. (https://doi. org/10.1111/j.1600-6143.2011.03756.x)

15 Fernandez Balsells M, Esmatjes E, Ricart MJ, Casamitjana R, Astudillo E \& Fernandez Cruz L. Successful pancreas and kidney transplantation: a view of metabolic control. Clinical Transplantation 199812 582-587.

16 Luzi L, Secchi A, Facchini F, Battezzati A, Staudacher C, Spotti D, Castoldi R, Ferrari G, Di Carlo V \& Pozza G. Reduction of insulin resistance by combined kidney-pancreas transplantation in type 1 (insulin-dependent) diabetic patients. Diabetologia 199033 549-556. (https://doi.org/10.1007/BF00404143)

17 DeFronzo RA, Tobin JD \& Andres R. Glucose clamp technique: a method for quantifying insulin secretion and resistance. American Journal of Physiology 1979237 E214-E223. (https://doi.org/10.1152/ ajpendo.1979.237.3.E214)

18 Matthews DR, Hosker JP, Rudenski AS, Naylor BA, Treacher DF $\&$ Turner RC. Homeostasis model assessment: insulin resistance and beta-cell function from fasting plasma glucose and insulin concentrations in man. Diabetologia 198528 412-419. (https://doi. org/10.1007/BF00280883)

19 Bilous RW, Mauer SM, Sutherland DE, Najarian JS, Goetz FC $\&$ Steffes MW. The effects of pancreas transplantation on the glomerular structure of renal allografts in patients with insulindependent diabetes. New England Journal of Medicine 1989321 80-85. (https://doi.org/10.1056/NEJM198907133210204)

20 Ojo AO, Held PJ, Port FK, Wolfe RA, Leichtman AB, Young EW, Arndorfer J, Christensen L \& Merion RM. Chronic renal failure after transplantation of a nonrenal organ. New England Journal of Medicine 2003349 931-940. (https://doi.org/10.1056/NEJMoa021744)

21 Le Dinh H, Deroover A, Coimbra C, Weekers L, Leonet J, Meurisse M \& Squifflet JP. Evolution of native kidney function after pancreas transplantation alone. Transplantation Proceedings $2012 \mathbf{4 4}$ 2829-2833. (https://doi.org/10.1016/j.transproceed.2012.09.094)

22 Mazur MJ, Rea DJ, Griffin MD, Larson TS, Prieto M, Gloor JM, Schwab TR, Textor SC, Nyberg SL \& Stegall MD. Decline in native renal function early after bladder-drained pancreas transplantation alone. Transplantation 200477 844-849. (https://doi.org/10.1097/01. TP.0000114607.62534.C9)

23 Genzini T, Marchini GS, Chang AJ, Antunes I, Hayashi A, Abensur H, Kataoka L, Crescentini F, Romao JE Jr, Rangel EB et al. Influence of pancreas transplantation alone on native renal function. Transplantation Proceedings 200638 1939-1940. (https://doi. org/10.1016/j.transproceed.2006.06.083)

24 Boggi U, Vistoli F, Amorese G, Giannarelli R, Coppelli A, Mariotti R, Rondinini L, Barsotti M, Piaggesi A, Tedeschi A et al. Results of pancreas transplantation alone with special attention to native kidney function and proteinuria in type 1 diabetes patients. Review of Diabetic Studies 20118 259-267. (https://doi.org/10.1900/ RDS.2011.8.259)

25 Midtvedt K, Hjelmesaeth J, Hartmann A, Lund K, Paulsen D, Egeland $\mathrm{T} \&$ Jenssen $\mathrm{T}$. Insulin resistance after renal transplantation: the effect of steroid dose reduction and withdrawal. Journal of the American Society of Nephrology 200415 3233-3239. (https://doi. org/10.1097/01.ASN.0000145435.80005.1E)

26 Dieterle CD, Schmauss S, Veitenhansl M, Gutt B, Illner WD, Land W \& Landgraf R. Glucose metabolism after pancreas transplantation: cyclosporine versus tacrolimus. Transplantation 200477 1561-1565. (https://doi.org/10.1097/01.TP.0000129063.65446.65) 
27 Duijnhoven EM, Boots JM, Christiaans MH, Wolffenbuttel BH \& Van Hooff JP. Influence of tacrolimus on glucose metabolism before and after renal transplantation: a prospective study. Journal of the American Society of Nephrology 200112 583-588.
28 Chatzizacharias NA, Vaidya A, Sinha S, Sharples E, Smith R, Jones G, Brockmann J \& Friend PJ. Risk analysis for deterioration of renal function after pancreas alone transplant. Clinical Transplantation 2012 26 387-392. (https://doi.org/10.1111/j.1399-0012.2011.01534.x)

Received 25 April 2018

Revised version received 9 July 2018

Accepted 30 July 2018 